\title{
Inéditos de Simões Lopes Neto: Terra gaúcha e Artinha de leitura
}

Terra gaúcha. Organização de Luís Augusto Fischer. Caxias do Sul/RS: Belas Letras, 2013. 275 p. Artinha de leitura. Organização de Luís Augusto Fischer. Caxias do Sul/RS: Belas Letras, 2013. 194 p.

Escritores gaúchos estão definitivamente incluídos no atual cenário da literatura brasileira. Para citar um dado concreto e recente, os vencedores dos prêmios Jabuti, Portugal Telecom e São Paulo de Literatura em 2013 são, respectivamente, Luis Fernando Verissimo, Cíntia Moscovich (categoria contos) e Daniel Galera, três gaúchos de nascimento ou adoção (no caso de Galera, paulista residente em Porto Alegre). Pode parecer coincidência, mas quem estuda a formação da literatura do Rio Grande do Sul vê essa efervescência como o ponto de chegada de um processo que vem se moldando há tempo. Luís Augusto Fischer, em recente artigo para a Folha de S.Paulo, ${ }^{1}$ defende motivos literários, históricos e geográficos que explicam a aparição simultânea de tantos gaúchos.

Literários: desde a metade do século XIX delineou-se no Rio Grande do Sul a base para a criação de um sistema literário, ou seja, autores produzindo obras regularmente e dedicados à criação de um mercado editorial, para usar um termo atual, que viabilizasse sua recepção pelo leitor. Esses escritores leem uns aos outros, absorvem influências e as modificam, de modo a configurar uma tradição que põe em funcionamento o sistema. Obviamente, seguem-se aqui as ideias de Antonio Candido. Históricos: uma tradição republicana, também fundada desde meados do XIX, que fortaleceu a escola e o acesso à literatura. Geográficos: a localização no extremo sul do Brasil, frio, em oposição ao clima tropical do centro, cercado por países hispânicos, alimentou no Rio Grande do Sul uma "utopia autonomista", nas palavras de Fischer, que somada àquela tradição republicana criou, em alguns casos, condenáveis comportamentos xenofóbicos, mas também precioso material literário.

1. FISCher, Luís Augusto. "A invasão sulina”. Folha de S.Paulo, 2. jun. 2013. Disponível em: <http:// www1.folha.uol.com.br/ilustrissima/2013/o6/1288350-a-invasao-sulina.shtml>. Acesso em: 4 jan. 2014. 
A chave da formação desse sistema sulino é Simões Lopes Neto, embora ele não tenha encontrado em seu tempo o sistema maduro de hoje que possibilita a autores como Verissimo, Moscovich e Galera a publicação, leitura e premiação de seus livros quase simultaneamente ao momento em que os escrevem. No entanto, essa mesma maturidade faz com que autores de gerações precedentes sejam redescobertos e revalorizados, e é o que vem acontecendo com Simões Lopes Neto.

Em 2012 comemorou-se o centenário de publicação de Contos gauchescos. Na cidade natal do escritor, Pelotas, ocorreram conferências com especialistas na obra simoniana, entre eles Flávio Loureiro Chaves e Carlos Francisco Sica Diniz. Mas o ponto alto desse ano de efemérides foi a publicação da edição anotada de Contos gauchescos e Lendas do Sul, pela L\&PM editores. Com introdução, fixação do texto e notas do já citado Luís Augusto Fischer, a edição passa a ser a definitiva para qualquer leitor interessado na obra de Simões.

Em 2013 o escritor pelotense continuou em pauta, não só pelo centenário de seu outro grande livro - Lendas do Sul - mas principalmente pela publicação dos até então inéditos Artinha de leitura e Terra gaúcha pela editora Belas Letras. Foi novamente Luís Augusto Fischer o responsável pela vinda a público desses inéditos, depois de um incansável trabalho de negociação, decifração e análise. ${ }^{2}$

A Artinha de leitura é uma cartilha escolar redigida por Simões em 1907. Dividida em cinco partes que vão da apresentação de vogais, formação de sílabas e palavras até pequenos textos com ensinamentos morais e orientações didáticas ao professor, a cartilha é em vários aspectos inovadora. Primeiramente porque eram raríssimas as iniciativas do tipo em solo brasileiro; o material didático adotado nas escolas existentes (em 1920, tínhamos 65\% de analfabetos na população com quinze anos ou mais) provinha, em sua maioria, de Portugal e ainda assim estava distante do livro de Simões. Mais que uma cartilha de alfabetização, Artinha de leitura é um projeto de formação de leitores, e isso fica muito claro nas duas últimas partes do livro: os contos morais e os conselhos ao professor. Notas como "o aprendiz lerá para si cada período, e depois em voz alta, com toda a correção explicará em seguida o que leu" (2013, p. 108) sugerem que a preocupação de Simões não é apenas com o treinamento de leitura, com a repetição de palavras e frases, e sim com a sua interpretação e expressão do entendimento do

2. Cf. Lopes neto, João Simões. Contos gauchescos e Lendas do Sul. Porto Alegre: L\&PM, 2012. Id. Artinha de leitura. Caxias do Sul/Rs: Belas Letras, 2013; Id. Terra gaúcha. Caxias do Sul/Rs: Belas Letras, 2013. 
aluno. As palavras dirigidas ao professor incentivam-no a adotar uma postura afetuosa e humanitária em relação ao aluno. Conselhos como "não ordene senão aquilo que pode ser executado" (2013, p. 142) ou "convém evitar uns tantos castigos" (2013, p. 144) vão na contramão da pedagogia da palmatória, tão característica ao período, e antecipam comportamentos que as correntes pedagógicas mais modernas darão como certos, na esteira dos ensinamentos de Paulo Freire.

Simões Lopes Neto pagou um preço alto por seu caráter inovador. Ele adotou na Artinha a reforma ortográfica que havia sido aprovada pela Academia Brasileira de Letras no mesmo ano de 1907 , confiando que ela rapidamente entraria em vigor. No entanto, isso não aconteceu e a cartilha foi recusada pelos órgãos competentes justamente por não seguir a ortografia vigente. Com essa negativa, Simões desistiu da ideia e o livro foi engavetado. Não se sabe muito bem como, mas o documento rejeitado foi parar em um sebo, onde foi comprado na década de 1970 pela professora gaúcha Helga Piccolo que, sem saber de seu valor, o depositou em sua biblioteca e somente em 2008, quando separava alguns livros para doação, deu-se conta da preciosidade que tinha em mãos. Encaminhou-o, então, à Universidade Federal de Pelotas que, por sua vez, o alojou no Instituto Simões Lopes Neto, também na cidade de Pelotas. Esse parece ser o destino final do manuscrito que só agora é publicado em livro, cento e seis anos depois de sua concepção.

Percurso também labiríntico fez o outro manuscrito que agora vira livro, Terra gaúcha. A viúva de Simões Lopes Neto, Francisca Meireles Leite, recebe pelo correio, nos anos 1940, um pacote remetido do Rio de Janeiro, onde o escritor passou sua juventude. Nesse pacote estavam os dois cadernos que agora compõem Terra gaúcha. Os cadernos passaram pelas mãos de empenhados estudiosos da obra de Simões, principalmente Manoelito de Ornellas, que atestou a veracidade do manuscrito ainda na década de 1940 e tentou uma publicação através do governo do Rio Grande do Sul que, mais uma vez, disse não à obra de Simões.

Assim como a Artinha, Terra gaúcha permaneceu engavetado por mais de um século, já que ambos os livros provavelmente foram concebidos na mesma época. Integram uma série maior projetada por Simões, a Série Brasiliana, composta por quatro volumes (além de Artinha de leitura e Terra gaúcha, estariam Eu, na escola e Hinos e Glórias do Brasil, como o escritor deixou registrado na folha de rosto da cartilha). $\mathrm{O}$ texto sobre os hinos brasileiros não foi escrito - ou ainda não encontrado - e é possível que Eu, na escola tenha sido incorporado a Terra gaúcha, porque este está justamente dividido em As férias, na estância e $O$ estudo, no colégio. 
Terra gaúcha é um livro de leitura escolar, planejado para ser um passo adiante em relação à Artinha na formação de leitores. Trata-se de obra de ficção, narrada pelo menino Maio, de mais ou menos dez anos, que conta suas peripécias de férias na estância da família - o mundo rural - e seus aprendizados no colégio - o mundo urbano. E o encontro entre esses dois mundos é traço fundamental da narrativa e da biografia de Simões Lopes Neto.

No que se refere à vida do autor, nasceu, como já dissemos, em Pelotas, sul do Rio Grande do Sul, em 1865. À época, Pelotas era considerada uma das cidades mais cosmopolitas do estado, com direta ligação com Paris, para onde as famílias mais abastadas enviavam seus filhos para estudarem e se educarem nas maneiras refinadas. Ao mesmo tempo, essas famílias mantinham suas fortunas a partir do trabalho nas charqueadas, onde se executava o abate do gado e a distribuição da carne. Assim, um mesmo indivíduo convivia tranquilamente com a rudeza do mundo das charqueadas e a elegância dos espetáculos e bailes quase parisienses nos teatros e salões de Pelotas.

Filho de uma dessas famílias proprietárias, Simões frequentou a estância do avô, a nobreza urbana pelotense, a capital do Império brasileiro e essa mescla aparece em sua literatura. Na juventude escreve peças de teatro que serão encenadas no imponente Sete de Abril (em funcionamento desde 1831), ou seja, literatura com temática e para consumo urbano. Na maturidade (e com a ruína financeira da família, fruto do declínio das atividades nas charqueadas após a modernização trazida pelo século $\mathrm{xx}$ ) vai dedicar-se ao tema gauchesco, à cultura popular rural que aparece em Contos gauchescos e Lendas do Sul, livros que o consagraram como escritor maior na literatura rio-grandense e brasileira.

Até 2013, essas eram as duas fases da obra de Simões Lopes Neto. Com a publicação desses dois inéditos, abre-se uma etapa intermediária, por assim dizer pedagógica, na narrativa do escritor. Nessa terceira fase, a cidade e o campo estão muito mais em diálogo, já que a Série Brasiliana é "dedicada às escolas urbanas e rurais" como Simões fez questão de deixar registrado na capa da Artinha. A estrutura de Terra gaúcha também indica essa conexão, toda ela mediada pelas impressões do menino Maio.

$\mathrm{Na}$ estância, Maio brinca com suas irmãs Araci e Ivoti (os nomes de origem indígena já demonstram interesse na formação mestiça do povo sul-rio-grandense), conhece o trato com o cavalo, o gado e a agricultura executados pelos agregados da família e pelo pai do narrador e, principalmente, ouve as histórias de siá Mariana, uma senhora (possivelmente mulata ou cabocla) que narra às crianças as lendas do Boi-tatá e do Negrinho do Pastoreio. Essa personagem - e não seria descabido interpretá-la 
como uma prefiguração da tia Nastácia de Monteiro Lobato - representa a tradição oral, os causos e lendas formadores do imaginário rio-grandense que Simões Lopes Neto explorará com competência e beleza em sua obra madura (as duas lendas narradas por siá Mariana reaparecerão na obra de 1913, Lendas do Sul).

Em O estudo, no colégio Maio conhece seus colegas de classe, cada um deles oriundo de um estado brasileiro. Nesse ponto, fica mais claro o civismo que permeia toda a obra; a ideia original de Simões era que cada aluno apresentasse as datas cívicas de seus estados, no entanto, apenas são mencionados os eventos de Rio de Janeiro e Mato Grosso, já que o manuscrito está inacabado. Assim, há uma aparente contradição entre o título do livro, Terra gaúcha, e o conteúdo dessa segunda parte, notadamente brasileiro, acompanhando as tendências nacionalistas que tomavam o país no princípio do século xx (Coelho Neto e Olavo Bilac são nomes aderidos à tendência).

Figura determinante do colégio de Maio é o Mestrinho, professor e espécie de diretor. Ele segue à risca aquelas orientações que Simões dava aos professores em Artinha de leitura: de comportamento sempre moderado e gentil, faz a defesa do diferente (um aluno canhoto ridicularizado pelos colegas é protegido pelo Mestrinho) e condena a violência (pune um aluno que agride outro). Novamente, a pedagogia humanista que Simões Lopes Neto prega nesses dois livros o localiza na vanguarda de seu tempo.

Vale a pena destacar o acerto de Simões Lopes Neto na escolha de um narrador menino. Tentando conquistar leitores também meninos, a correspondência de faixa etária certamente seria fator de identificação imediata pelo leitor, caso o livro tivesse circulado na época em que foi escrito. É lamentável que a publicação tardia não recupere esse aspecto do texto, já que as crianças do século XXI são muito diferentes de Maio. Aliás, a criação certeira de narradores é um dos pontos altos da ficção de Simões; o êxito literário de Contos gauchescos deve-se muito à narração de Blau Nunes, um velho gaúcho que descreve sua saga, mesclada à história do Rio Grande do Sul, a um interlocutor externo ao mundo em que vive.

Enfim, a publicação de Artinha de leitura e Terra gaúcha inaugura uma nova vertente de estudos simonianos, voltados ao projeto pedagógico do autor. Além disso, a edição preparada por Luís Augusto Fischer e executada pela editora Belas Letras tem tudo para tornar-se objeto de colecionador. Em capa dura, com reprodução dos manuscritos e ensaios de pesquisadores envolvidos na recuperação e interpretação do material (os professores Pedro de Moraes Garcez e Beatriz Ana Loner para Artinha; Carlos Francisco Sica Diniz e Fausto José Leitão Domingues, para Terra gaúcha, além 
do próprio Fischer), o projeto editorial é refinadíssimo, o que lhe rendeu, aliás, o prêmio Açorianos 2013, o mais importante do Rio Grande do Sul.

O conjunto Artinha de leitura e Terra gaúcha foi considerado o livro do ano em 2013 neste mesmo prêmio Açorianos. Obteve, portanto, o merecido reconhecimento no Rio Grande do Sul. Seria muito justo que, assim como Luis Fernando Veríssimo, Cíntia Moscovich e Daniel Galera, Simões Lopes Neto fosse cada vez mais lembrado e estudado no centro do país, já que é figura fundadora dessa linhagem de gaúchos que hoje saudamos orgulhosamente.

Karina de Castilhos Lucena é professora do Instituto de Letras da UFRGS. 